\title{
Quantitative PET Studies of the Serotonin Transporter in MDMA Users and Controls Using [ $\left.{ }^{1} \mathrm{C}\right] \mathrm{McN} 5652$ and $\left[{ }^{\prime \prime} \mathrm{C}\right] \mathrm{DASB}$
}

\author{
Una D McCann*,', Zsolt Szabo ${ }^{2}$, Esen Seckin², Peter Rosenblatt ${ }^{3}$, William B Mathews², Hayden T Ravert ${ }^{2}$, \\ Robert F Dannals ${ }^{2}$ and George A Ricaurte ${ }^{3}$ \\ 'Department of Psychiatry, The Johns Hopkins School of Medicine, Baltimore, MD, USA; ${ }^{2}$ Department of Radiology, The Johns Hopkins School of \\ Medicine, Baltimore, MD, USA; ${ }^{3}$ Department of Neurology, The Johns Hopkins School of Medicine, Baltimore, MD, USA
}

\begin{abstract}
( \pm )3,4-Methylenedioxymethamphetamine (MDMA, 'Ecstasy') is a widely used illicit drug that produces toxic effects on brain serotonin axons and axon terminals in animals. The results of clinical studies addressing MDMA's serotonin neurotoxic potential in humans have been inconclusive. In the present study, 23 abstinent MDMA users and 19 non-MDMA controls underwent quantitative positron emission tomography (PET) studies using [ ' $\mathrm{C}$ ]McN5652 and [ ' $\left.{ }^{\prime} \mathrm{C}\right] \mathrm{DASB}$, first- and second-generation serotonin transporter (SERT) ligands previously validated in baboons for detecting MDMA-induced brain serotonin neurotoxicity. Global and regional distribution volumes (DVS) and two additional SERT-binding parameters ( $D V_{\text {spec }}$ and DVR) were compared in the two subject populations using parametric statistical analyses. Data from PET studies revealed excellent correlations between the various binding parameters of [ ${ }^{\prime \prime} \mathrm{C}$ ] McN5652 and [ ' $\mathrm{C}$ ]DASB, both in individual brain regions and individual subjects. Global SERT reductions were found in MDMA users with both PET ligands, using all three of the above-mentioned SERT-binding parameters. Preplanned comparisons in 15 regions of interest demonstrated reductions in selected cortical and subcortical structures. Exploratory correlational analyses suggested that SERT measures recover with time, and that loss of the SERT is directly associated with MDMA use intensity. These quantitative PET data, obtained using validated first- and second-generation SERT PET ligands, provide strong evidence of reduced SERT density in some recreational MDMA users.
\end{abstract}

Neuropsychopharmacology (2005) 30, I74I-1750. doi: I0.1038/sj.npp. I300736; published online 20 April 2005

Keywords: MDMA; neurotoxicity; serotonin transporters; drug abuse; PET; neuroimaging

\section{INTRODUCTION}

$( \pm)$ 3,4-Methylenedioxymethamphetamine (MDMA, 'Ecstasy') is a popular drug of abuse (Johnston et al, 2004) that produces toxic effects on brain serotonin neurons in animals. In particular, animals treated with MDMA demonstrate persistent reductions in regional brain concentrations of serotonin (Schmidt, 1987; Schmidt et al, 1986), its major metabolite, 5-hydroxyindoleacetic acid (5-HIAA), (Commins et al, 1987; Schmidt, 1987) its ratelimiting enzyme, tryptophan hydroxylase (TPH), (Schmidt and Taylor, 1987; Stone et al, 1987, 1986), its transporter, SERT (Battaglia et al, 1988, 1987; Commins et al, 1987), and

*Correspondence: Dr UD McCann, Department of Psychiatry, The Johns Hopkins School of Medicine, 550I Nathan Shock Drive, Baltimore, MD 21224, USA, Tel: 410550 1972, Fax: 4105500030 , E-mail: umccann@jhmi.edu

Received 28 September 2004; revised 19 January 2005; accepted I March 2005

Online publication: 4 March 2005 at http://www.acnp.org/citations/ Npp03040504045 I/default.pdf vesicular monoamine transporters (VMATs) (McCann et al, 2000). Additionally, immunocytochemical techniques demonstrate a loss of serotonin axons and axon terminals in MDMA-treated animals, suggesting that losses of serotonin axonal markers are related to a distal axotomy of brain serotonin neurons (McCann et al, 2000; O'Hearn et al, 1988; Yuan et al, 2004). This view is supported by recent tracttracing studies which demonstrate reduced anterograde $\left[{ }^{3} \mathrm{H}\right]$ proline transport from rostral raphe nuclei to various regions of the forebrain in MDMA-treated animals (Callahan et al, 2001). Taken together, neurochemical, neuroanatomical, and axon-tracing methods provide compelling evidence that MDMA is toxic toward brain serotonin axons and axon terminals in animals.

Clinical studies that have assessed abstinent MDMA users for evidence of toxic effects on brain serotonin neurons have yielded suggestive, but inconclusive, findings. For example, abstinent MDMA users, like monkeys with documented serotonin neurotoxicity (Ricaurte et al, 1988; Taffe et al, 2002) have reduced levels of CSF 5-HIAA (McCann et al, 1999, 1994) but reductions in CSF 5-HIAA 
could represent persistent alterations in serotonin metabolism, rather than neurotoxicity. Positron emission tomography (PET) studies with $\left[{ }^{11} \mathrm{C}\right] \mathrm{McN} 5652$ have also demonstrated reductions in brain SERT in abstinent MDMA users (Buchert et al, 2003, 2004; McCann et al, 1998), but these studies have had limitations. In particular, our study (McCann et al, 1998) applied a method for determination of the plasma input function of the radioligand that led to high estimates of SERT density, and were associated with a high degree of variability that necessitated use of logarithmic transforms to permit parametric statistical analyses. The studies by Buchert et al $(2003,2004)$ did not include determination of the arterial input function for quantitative PET analysis but, rather, used the cerebellum as a reference region to correct for nonspecific binding. While this latter method permits assessment of the relative density of subcortical SERT-rich brain regions, it precludes assessment of cortical SERT density. Imaging studies using SPECT methods have also demonstrated a loss of the SERT in MDMA users (Haddad et al, 2002; Reneman et al, 2001a,b; Semple et al, 1999), but the utility of SPECT for detecting loss of cortical SERT has not been validated.

Recent studies in baboons (Szabo et al, 2002) and humans (Frankle et al, 2004; Houle et al, 2000; Meyer et al, 2001; Wilson et al, 2000) have demonstrated the suitability of a new SERT ligand, $\left[{ }^{11} \mathrm{C}\right] \mathrm{DASB}$, for studying serotonin neurons in the living brain. $\left[{ }^{11} \mathrm{C}\right] \mathrm{DASB}$ appears to have two critical advantages over $\left[{ }^{11} \mathrm{C}\right] \mathrm{McN} 5652$, including a greater specific-to-nonspecific equilibrium activity ratio, and a measurable plasma-free fraction for use in tracer modeling (Frankle et al, 2004). These advantages may be helpful in detecting differences in regions of the brain with relatively low SERT density, such as the neocortex. The purpose of the present study was two-fold: (1) to conduct and compare PET studies with $\left[{ }^{11} \mathrm{C}\right] \mathrm{McN} 5652$ and $\left[{ }^{11} \mathrm{C}\right] \mathrm{DASB}$ in abstinent MDMA users and matched controls using quantitative methods and (2) to explore the possibility that MDMA use parameters, such as lifetime exposure and duration of abstinence, are related to SERT binding in MDMA users.

\section{METHODS AND MATERIALS}

\section{Subject Recruitment}

Subjects were recruited by advertisements posted in newspapers, fliers, radio, and the worldwide web. A number of subjects were also recruited by word-of-mouth, from previous participants. Potential subjects underwent an initial telephone screen to determine demographics, medical histories, drug and alcohol use histories, and psychiatric histories. Those subjects who appeared to meet inclusion criteria were invited to come for a face-to-face screening, which involved assessment using the SCID-IV (First et al, 1996) by a trained member of the research team, a physical examination, routine blood chemistries, blood clotting studies, and urine and blood screens for drugs of abuse. Female subjects underwent urine pregnancy tests prior to undergoing PET procedures. The study was approved by the Johns Hopkins Medicine Institutional Review Board and the Johns Hopkins Bayview Medical
Center General Clinical Research Center Advisory Board. All subjects provided written informed consent.

Subjects were in good medical health, had normal clotting studies, negative urine and blood drug screens for illicit drugs (other than marijuana, which can be detected in urine for 3 weeks after use), and reported no illicit drug use for at least 2 weeks prior to study participation. MDMA subjects reported having used MDMA on at least 25 separate occasions. Control subjects reported that they had never previously used MDMA. Both groups were permitted to have used other recreational drugs (but none in the 2 weeks prior to study participation). No subjects met criteria for psychiatric illnesses in which serotonin has been implicated (ie major depression, obsessive compulsive disorder, panic disorder, generalized anxiety disorder, generalized social phobia, bipolar disorder, any psychotic disorder). No subject met criteria for past or present alcoholism or current drug dependence.

\section{Imaging Procedures}

MRI protocol. To ensure reproducibility of positioning during the repeated PET studies, a custom-made face mask (TRU-SCAN, Annapolis, MD) was fitted to subjects' heads, which were then attached to the head holder during the PET scans. Two MRI sequences were obtained using a Signa 1.5$\mathrm{T}$ scanner (General Electric Medical Systems, Milwaukee, WI). The first sequence was a set of T1-weighted scout images with the following parameters: repetition time $(\mathrm{TR})=500 \mathrm{~ms}$, echo time $(\mathrm{TE})=20 \mathrm{~ms}, 5-\mathrm{mm}$ slice thickness with no gap, $128 \times 256$ matrix, and 1 excitation. The second sequence was an axial spin-density/T1-weighted three-dimensional volumetric scan using radiofrequency spoiled gradient (SPGR) echoes. The parameters were as follows: $\mathrm{TR}=35 \mathrm{~ms}, \mathrm{TE}=5 \mathrm{~ms}$, flip angle $=45^{\circ}, 1.5-\mathrm{mm}$ effective slice thickness, no gap, 124 slices with in-plane $192 \times 256$ matrix, $15-\mathrm{cm}$ field of view and 1 excitation. The purpose of the SPGR sequence was to ensure precise positioning and to achieve image registration with PET for localization of the structures of interest (Szabo et al, 1999).

PET protocol. An Advance PET camera (General Electric) with an axial resolution (full width at half maximum) of $5.8 \mathrm{~mm}$ and an in-plane resolution of $5.4 \mathrm{~mm}$ was used for image acquisition. This scanner acquires 35 simultaneous slices of $4.25-\mathrm{mm}$ thickness, enclosing a total longitudinal field of view of $15 \mathrm{~cm}$. A transmission scan was obtained with twin $370-\mathrm{MBq}(10 \mathrm{mCi}){ }^{68} \mathrm{Ge}$ pin sources for $10 \mathrm{~min}$ and was used for attenuation correction of the subsequent emission PET scans. $\left[{ }^{11} \mathrm{C}\right] \mathrm{McN} 5652$ and $\left[{ }^{11} \mathrm{C}\right] \mathrm{DASB}$ were prepared according to published methods (Wilson et al, 2000; Suehiro et al, 1992). Two PET studies were performed for each subject: one study employed $\left[{ }^{11} \mathrm{C}\right] \mathrm{McN} 5652$, at $446 \pm 32 \mathrm{MBq}$, and the other employed $\left[{ }^{11} \mathrm{C}\right] \mathrm{DASB}$, at $448 \pm 31 \mathrm{MBq}$. The time difference between the injections was approximately $135 \mathrm{~min}$. At the time of injection, specific activities for $\left[{ }^{11} \mathrm{C}\right] \mathrm{McN} 5652$ were $534 \pm 367 \mathrm{GBq} / \mu \mathrm{mol}$, and those for $\left[{ }^{11} \mathrm{C}\right] \mathrm{DASB}$ were $593 \pm 338 \mathrm{GBq} / \mu \mathrm{mol}$. A total of 18 serial dynamic PET images were acquired during the first $95 \mathrm{~min}$ after injection of each radioligand using the following image sequence: $4 \times 15 \mathrm{~s}$ frames, $3 \times 1 \mathrm{~min}$ frames, 
$3 \times 2$ min frames, $3 \times 5$ min frames, $3 \times 10$ min frames, and $2 \times 20$ min frames. Correct positioning of subjects' heads was monitored by a laser guide. PET scans were reconstructed using ramp-filtered backprojection in a $128 \times 128$ matrix, with a transaxial pixel size of $2 \times 2 \mathrm{~mm}$.

Input function. Before PET studies, a radial artery line was placed by an anesthesiologist and was kept open with heparinized high-pressure normal saline. To obtain the input function, blood samples were collected from a radial artery every $5 \mathrm{~s}$ during the first $2 \mathrm{~min}$ and then collected with increasing time intervals of 1-5 min until the end of the study, 95-min postinjection. Exact times of blood sampling were recorded. The input function was corrected for metabolized radioligand activity using 2-ml arterial plasma samples obtained at 5, 15, 30,60, and 90 min after injection, and analyzed for tracer metabolism. The extent of metabolism of $\left[{ }^{11} \mathrm{C}\right] \mathrm{McN} 5652$ and $\left[{ }^{11} \mathrm{C}\right] \mathrm{DASB}$ was determined as described previously (Hilton et al, 2000; Szabo et al, 2004).

Regions of interest. A total of 15 regions of interest were drawn by a neurologist (ES) who was blind to the group designation of the subject, using multiple coregistered SPGR MRI scan slice pairs. PET and MRI images were coregistered before the regions of interest were drawn using a software package developed at our institution. An early step in this program is compression of the 4D PET data set into a $3 \mathrm{D}$ data set (ie summing all individual scans into one scan and eliminating the time vector). Therefore, the PET scans used for registration represent an average of all $95 \mathrm{~min}$. These summed images contain activity in both cortical and subcortical regions sufficient for registration with MRI.

The 15 regions of interest included in our analyses were: amygdala, hippocampus, midbrain, ventral pons, dorsal pons, anterior cingulate gyrus, posterior cingulate gyrus, orbitofrontal cortex, dorsolateral frontal cortex, parietal cortex, occipital cortex, temporal cortex, thalamus, head of caudate, and putamen. More specifically, the amygdala, hippocampus, and midbrain (drawn as a rectangle between colliculi and pedunculi) were drawn using transaxial sections, whereas the ventral pons and dorsal pons were identified on sagittal sections. The anterior and posterior halves of the cingulate gyrus were identified on sagittal sections. Cortical regions were defined using coronal sections, with orbitofrontal and dorsolateral frontal cortices defined using the anterior pole of the corpus callosum as the anatomic landmark delineating the posterior boundaries for these regions, and the sulcus between the triangular and orbital portions of the inferior frontal gyrus as the boundary separating these two regions. The thalamus, head of caudate and putamen were drawn by following their anatomical boundaries on transaxial sections. The cerebellum was used as a reference region, but was not included as a region of interest for statistical purposes.

Although PET and MRI images were displayed simultaneously during definition of the regions of interest, multiple factors assured that the individual who drew the regions of interest maintained her blinded status. In particular, (1) this person was blinded to the group designation of the individual whose scan she was evaluating; (2) ROIs were drawn solely on the basis of MRI data using the anatomical boundaries, and the PET image was only displayed to check that the software-driven registration was appropriate; and (3) PET images were normalized to their own maximum so that it was not possible to tell if tracer accumulation was normal or decreased.

Tracer kinetic modeling. Radioligand binding was quantified by the (apparent) total distribution volume $(D V)$ represented by the ratio $D V=K_{1} / k_{2}$, where $K_{1}$ represented radioligand uptake into brain tissue and $k_{2}$ represented radioligand release from the brain tissue. $K_{1}$ and $k_{2}$ were estimated using the Marquardt error minimization algorithm (Marquardt, 1963) and a single tissue compartmental model (Szabo et al, 1999). The impulse response function that builds the kernel of this model is described by a blood volume component $B V$ and the two parameters $K_{1}$ and $k_{2}$. To increase the stability of estimating $K_{1}$ and $k_{2}, B V$ was preset to 0.05 to correspond to an average blood volume of $5 \%$ in brain tissue. $D V$ was expressed in units of $\mathrm{ml}$ (virtual ligand binding space)/ml (tissue space).

In addition to $D V$, the following parameters were calculated for group comparisons: distribution volume of specific binding $\left(D V_{\text {spec }}\right)$, calculated by subtracting the $D V$ measured in the cerebellum from each regional $D V$ and the distribution volume ratio $(D V R)$, calculated by dividing the regional $D V$ by the $D V$ of the cerebellum. The purpose of these normalizations is to minimize parameter bias caused by nonspecific binding, and taking into account that SERT-binding sites within the cerebellum are relatively small in number (although, notably, are known to decrease significantly following exposure to MDMA) (Szabo et al, 2004). Each of these ways of calculating radioligand binding involves different assumptions, and we included statistical tests for these measures to determine the robustness of our findings in the face of these different assumptions.

Statistical methods. To compare SERT binding in the 15 regions of interest in MDMA users and controls, an analysis of variance was conducted, with group (MDMA vs control) and brain region (each of the 15 predesignated regions of interest) as fixed variables, and SERT binding as the dependent variable. When significant main effects of group or region were found, or when a significant group by region interaction was seen, preplanned comparisons were conducted, comparing SERT binding in each of the 15 brain regions in the two groups (two-tailed tests). The possibility that SERT density, as measured by $\left[{ }^{11} \mathrm{C}\right] \mathrm{DASB}$ or $\left[{ }^{11} \mathrm{C}\right] \mathrm{McN} 5652$, might be associated with MDMA use variables was explored by correlational analyses. In particular, Pearson's product moment correlations were performed to determine the potential relationship between global and regional SERT-binding parameters (ie in cortical and subcortical structures), and MDMA use parameters. Analyses were based on a hypothesized positive correlation between SERT binding and duration of abstinence, and a negative hypothesized correlation between SERT binding and MDMA use intensity (one-tailed tests). All statistical tests were conducted using SPSS (Chicago, Il). 


\section{RESULTS}

In total, 23 abstinent MDMA users (10 female and 13 male subjects) and 19 control subjects (11 female and eight male subjects) participated in the study. Demographics and drug use histories of the two subject groups are shown in Table 1. On average, MDMA users had used MDMA on 97 separate occasions over a period of approximately 3 years but, on average, had not used MDMA for nearly 5 months. Groups were well matched with regard to age and level of education. Despite efforts to match subjects for 'other drugs of abuse', MDMA users, as a group, used more drugs than controls.

In keeping with previous findings (Frankle et al, 2004; McCann et al, 1998) regional binding of both radioligands was consistent with the known distribution of the brain SERT in humans. There was an excellent correlation between the $D V$ s of $\left[{ }^{11} \mathrm{C}\right] \mathrm{McN} 5652$ and $\left[{ }^{11} \mathrm{C}\right] \mathrm{DASB}$ in the various brain regions evaluated (overall $r=0.97$; Control $r=0.96$; MDMA $r=0.98$; Figure 1 ). There was also a significant correlation within individual subjects (overall $r=0.55$, Control $r=0.53$; MDMA $r=0.49$; Figure 2).

Significant main effects of group and region were noted for all three SERT-binding parameters for both SERT radioligands (Figure 3; Table 2), reflecting significantly lower mean SERT binding in MDMA users. There were no significant group $\times$ region interactions. Differences in $K_{1}$ between groups were not significant for either tracer

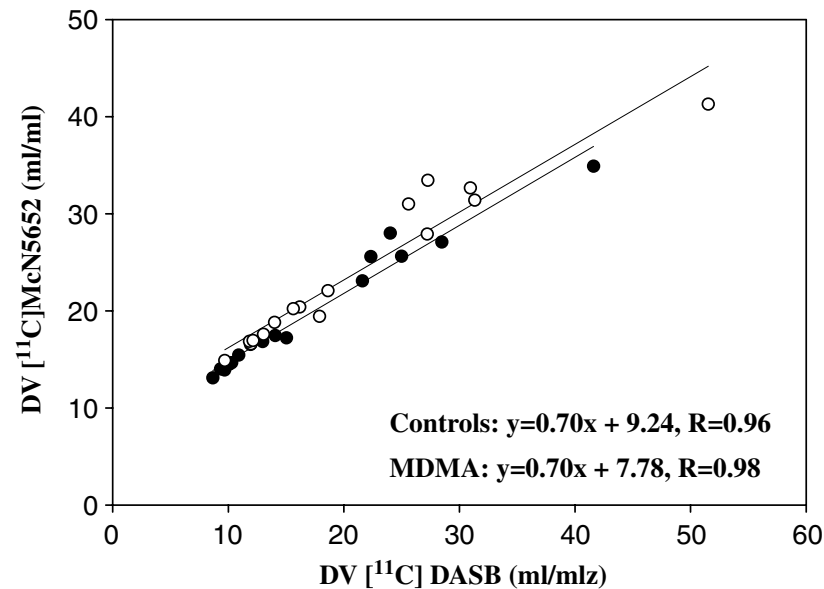

Figure I Correlation between DV [ [ C]DASB (x-axis) and DV $\left[{ }^{\prime \prime} \mathrm{C}\right] \mathrm{McN} 5652$ (y-axis) binding in regions of interest in control (open circles) and MDMA subjects (closed circles).

Table I Subject Demographics

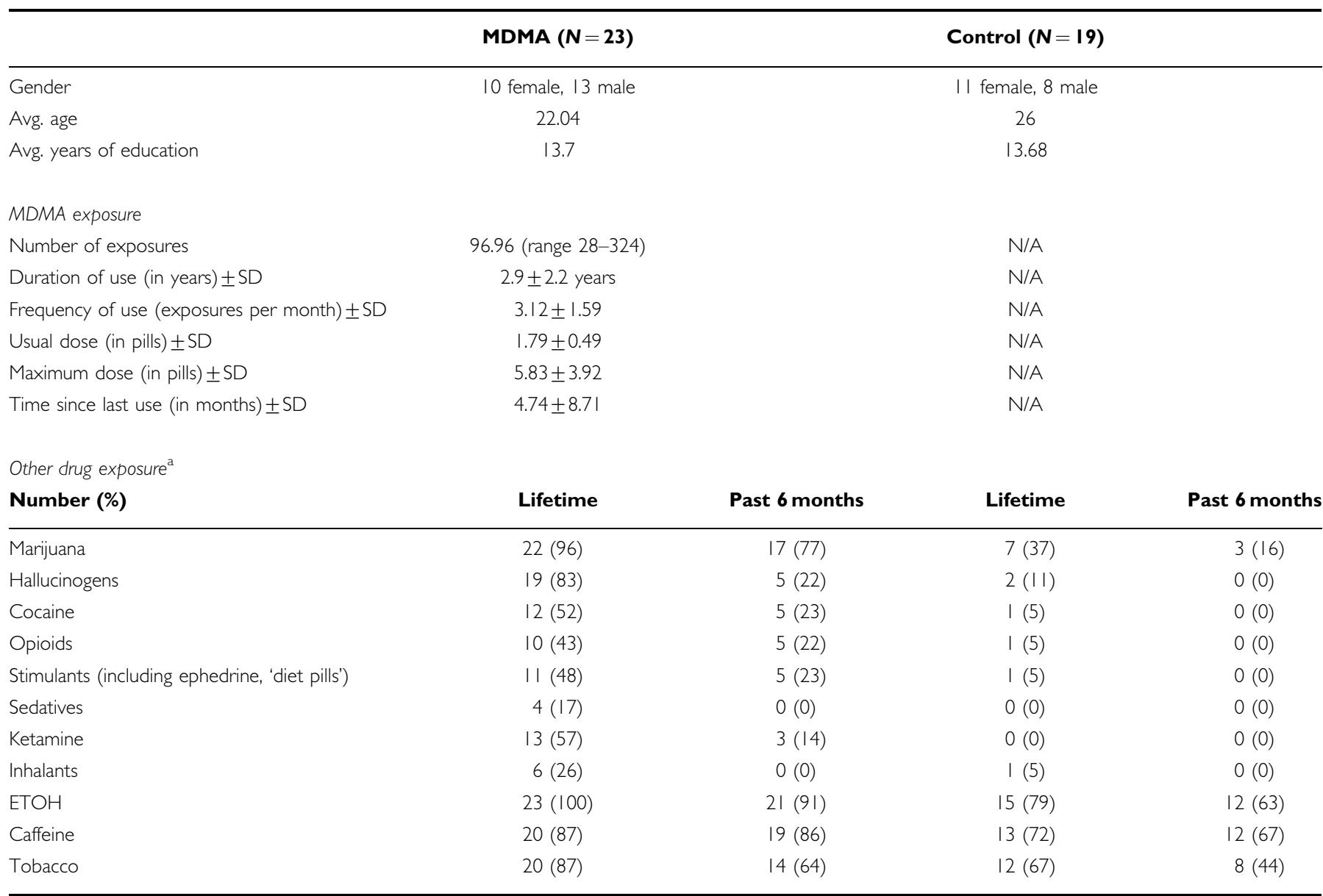

aSome MDMA subjects were unable to remember with certainty whether their most recent use of some 'other drugs' had occurred within the past 6 months. Only data on those subjects who provided specific information is included (ie 22, rather than 23, subjects were included for some 'other drugs'). In addition, caffeine and tobacco use data were not collected from one control subject. 
$\left(\left[{ }^{11} \mathrm{C}\right] \mathrm{DASB} \quad \mathrm{F}=1.68, p=0.125 ;\left[{ }^{11} \mathrm{C}\right] \mathrm{McN} 5652 \mathrm{~F}=1.599\right.$, $p=0.162$ ). When preplanned comparisons of regional brain SERT binding in the two groups were applied, significant differences in $D V$ were revealed in 12 of 15 regions for $\left[{ }^{11} \mathrm{C}\right] \mathrm{McN} 5652$, and nine of 15 regions for $\left[{ }^{19} \mathrm{C}\right] \mathrm{DASB}$ (Figure 4, Table 3). Results with $D V R$ and $D V_{\text {spec }}$ were quite similar, and generally led to decreased variability in binding values, particularly for $\left[{ }^{11} \mathrm{C}\right] \mathrm{DASB}$ (Figure 4).

As there is no general consensus regarding the optimal binding parameter for either $\left[{ }^{11} \mathrm{C}\right] \mathrm{McN} 5652$ or $\left[{ }^{11} \mathrm{C}\right] \mathrm{DASB}$, the ability of the three imaging parameters to detect differences between groups was assessed. In the current study, use of the $D V_{\text {spec }}$ parameter for $\left[{ }^{11} \mathrm{C}\right] \mathrm{McN} 5652$ led to decreased variability in SERT binding and, therefore, increases in the degree of statistical significance relative to the $D V$ parameter (the exceptions being amygdala and orbitofrontal cortex); whereas for $\left[{ }^{11} \mathrm{C}\right] \mathrm{DASB}$, use of both

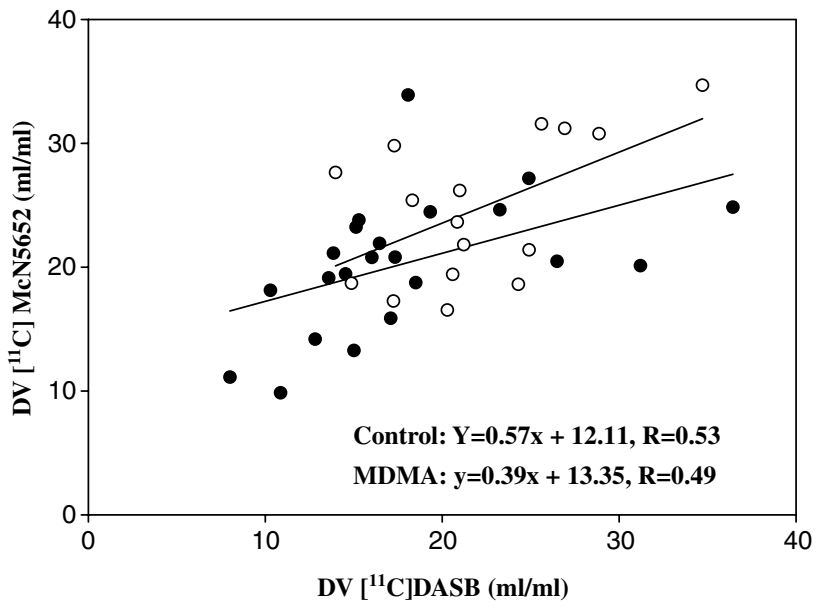

Figure 2 Correlation between DV [ $\left.{ }^{1} \mathrm{C}\right] \mathrm{DASB}(x$-axis; $\mathrm{ml} / \mathrm{ml})$ and DV [ I C]McN5652 (y-axis; $\mathrm{ml} / \mathrm{ml})$ binding within individual research subjects (Controls: open circles; MDMA: closed circles). the $D V R$ and $D V_{\text {spec }}$ binding parameters led to reductions in SERT-binding variability and increased ability in detecting significant differences in regional SERT binding between groups (significant differences found in 10 of 15 regions for both $D V R$ and $\left.D V_{\text {spec }}\right)$. These data suggest that the advantages of using cerebellar SERT binding as a 'nonspecific' binding reference may outweigh the disadvantages, despite the fact that the cerebellum is not void of SERT sites, which have been shown to be sensitive to MDMA-induced neurotoxicity (Szabo et al, 2002). Although results using the two radiotracers were highly consistent, the level of significance found with $\left[{ }^{11} \mathrm{C}\right] \mathrm{DASB}$ was generally greater than that for $\left[{ }^{11} \mathrm{C}\right] \mathrm{McN} 5652$.

Exploratory analyses evaluating a possible relationship between MDMA use parameters and SERT binding revealed significant relationship between global $\left[{ }^{11} \mathrm{C}\right] \mathrm{McN} 5652$ $D V_{\text {spec }}$ (ie mean $D V_{\text {spec }}$ of all 15 regions of interest) and duration of abstinence $(r=0.418 ; p=0.026)$, as well as global $\left[{ }^{11} \mathrm{C}\right] \mathrm{McN} 5652 \quad D V R$ and duration of abstinence $(r=0.494 ; p<0.010)$. In addition, global SERT binding $D V R$ was inversely correlated with typical monthly MDMA dose for both $\left[{ }^{11} \mathrm{C}\right] \mathrm{McN} 5652$ and $\left[{ }^{11} \mathrm{C}\right] \mathrm{DASB}(r=-0.38$ and -0.37 , respectively; $p=0.04$ for both radioligands).

\section{DISCUSSION}

The present results indicate that humans who report having used MDMA on at least 25 previous separate occasions (but no MDMA within the previous 2 weeks) have global reductions in binding of $\left[{ }^{11} \mathrm{C}\right] \mathrm{McN} 5652$ and $\left[{ }^{11}\right] \mathrm{DASB}$ to the brain SERT. Results obtained with the two selective SERT radiotracers were highly consistent, although, overall, $\left[{ }^{11} \mathrm{C}\right]$ DASB appears better suited for detecting statistically significant MDMA-associated reductions in brain SERT density in humans. When considered with the large body of preclinical literature demonstrating the toxic potential of MDMA toward brain serotonin neurons (see Introduction),

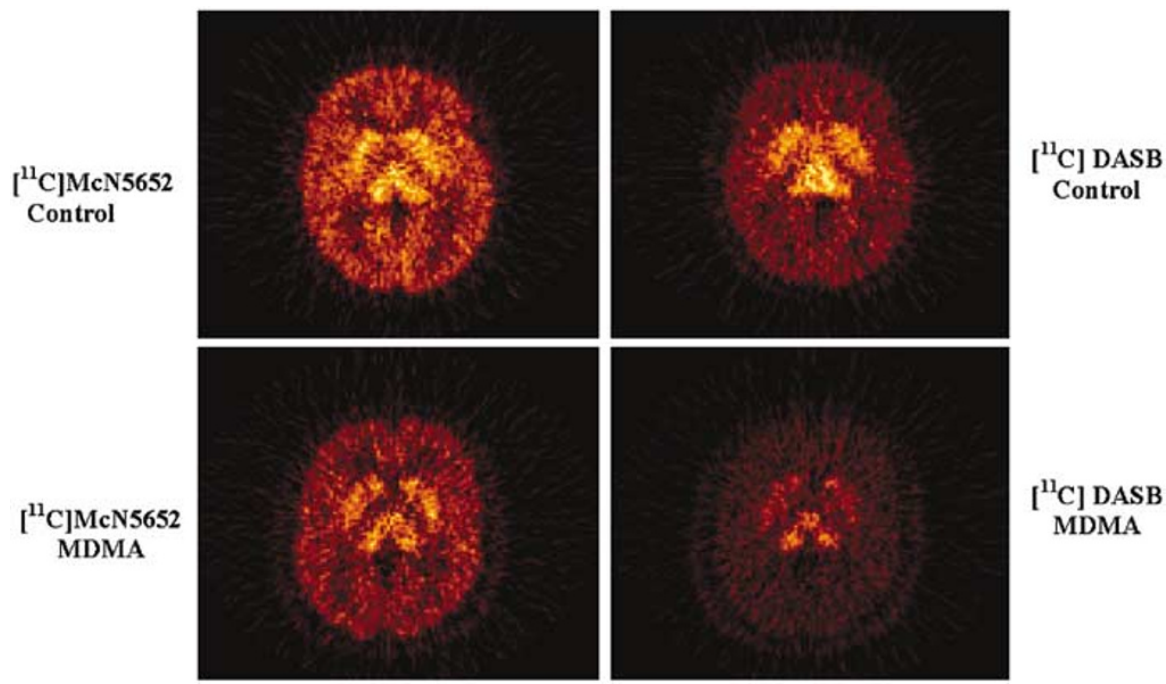

Figure 3 PET images obtained 75-95 min postinjection of [ ' $\mathrm{C}] \mathrm{McN5652}$ and [ ' $\mathrm{C}$ DASB in a representative control subject and a representative MDMA subject, demonstrating the reductions in SERT binding in the MDMA subject with both radioligands. PET images are normalized to a common maximum. 
Table 2 Results from ANOVA of SERT-Binding Parameters in MDMA Users and Controls with [ [ 'C]McN5652 and [ ' C]DASB

\begin{tabular}{|c|c|c|c|}
\hline Effect & $\begin{array}{c}D V \\
F(p \text {-value })\end{array}$ & $\begin{array}{c}D V_{\text {spec }} \\
F(p \text {-value })\end{array}$ & $\begin{array}{c}\text { DVR } \\
F(p \text {-value })\end{array}$ \\
\hline \multicolumn{4}{|l|}{$\left[{ }^{\prime \prime} C\right]$ McN5652 } \\
\hline Group & $5.3(p=0.028)$ & $6.6(p=0.014)$ & $5.9(p=0.02)$ \\
\hline Region & $172.8(p<0.00 \mid)$ & $172.8(p<0.00 \mid)$ & $296.4(p<0.001)$ \\
\hline Group $\times$ Region & $1.8(p=0.16)$ & $1.8(p=0.16)$ & $0.9(p=0.45)$ \\
\hline \multicolumn{4}{|l|}{$\left[{ }^{\prime \prime} C\right] \mathrm{DASB}$} \\
\hline Group & $4.1(p=0.05)$ & $5.0(p=0.03 \mid)$ & $7.4(p=0.01)$ \\
\hline Region & $139.6(p<0.00 \mid)$ & $139.6(p<0.00 \mid)$ & $267.8(p<0.001)$ \\
\hline Group $\times$ Region & $1.4(p=0.25)$ & $1.4(0=0.25)$ & $1.4(p=0.25)$ \\
\hline
\end{tabular}

the most parsimonious explanation for SERT reductions in MDMA users is that it is related to MDMA-induced toxicity to serotonin axons and axon terminals. However, it should be noted that subjects who participated in this study had used MDMA on at least 25 separate occasions and, on average, had used it on 97 separate occasions. Therefore, conclusions regarding MDMA-induced SERT reductions in individuals with lower levels of MDMA exposure than those included in this study cannot be reached.

The present results are largely in agreement with the recent voxel-based analysis of MDMA users by Buchert et al (2004), who found significant reductions of $\left[{ }^{11} \mathrm{C}\right] \mathrm{McN} 5652$ binding in a variety of brain regions in MDMA users (who were abstinent at the time of scanning), as well as a correlation between $\left[{ }^{11} \mathrm{C}\right] \mathrm{McN} 5652$ binding and duration of abstinence (in current MDMA users as well as those with protracted abstinence). Notably, their study failed to find group differences in SERT binding between controls and MDMA users who, on average, had abstained from use of MDMA for 18 months. The reasons for the absence of detectable differences between long-term abstinent MDMA users and controls in their study (as compared to data from the present study) could be related to several factors. These include the longer average duration of abstinence in their subjects (18 vs 4 months, on average) and possible regeneration of serotonergic axons over time, differences in analytic methods (quantitative $v s$ nonquantitative), and differences in spatial resolution (SPM requires normalization of brain volumes and, therefore, has reduced spatial resolution).

Of note, PET measures of the SERT, whether obtained using $\left[{ }^{11} \mathrm{C}\right] \mathrm{DASB}$ or $\left[{ }^{11} \mathrm{C}\right] \mathrm{McN} 5652$, are known to underestimate the extent of MDMA-induced reductions in the SERT, and percent reductions of BP potential do not correspond 1:1 with reductions of the SERT measured in vitro (Scheffel et al, 1998; Szabo et al, 2002). Measurements of the SERT in areas of the brain with relatively low SERT density, such as the neocortex, are particularly vulnerable to 'noise' introduced by more richly innervated subcortical regions, decreasing the ability to discern differences between subject groups. In addition to the problem of region-to-region 'spillover,' several additional sources of variability decrease the power to detect significant differ- ences between groups. These include signal-to-noise variability of the radioligand, intersubject variability (ie there is a range of 'normal' SERT binding in control subjects, as well as a range of presumed MDMA-induced changes in SERT binding), interscan variability, and variability associated with each of the factors employed in the model used to estimate SERT binding, to name a few. That having been said, the finding that two distinct radioligands employed within the same subject yield highly consistent global and regional PET data speaks strongly to the validity of the results herein reported.

The biologic significance of the observed SERT reductions is uncertain. However, as noted above, percent reductions in PET-binding parameters (Table 3) tend to underestimate the true extent of SERT loss, as evidenced by the fact that in baboon they are approximately $50 \%$ of those measured in vitro in the same animals (Scheffel et al, 1998; Szabo et al, 2002). Recognizing that percent reductions in PET-binding parameters may not precisely gauge the extent of SERT loss, the issue of biological significance, to a large degree, remains to be determined. From a functional standpoint, the absence of overt clinical consequences in our subjects could be taken to suggest that MDMA-induced SERT loss does not lead to gross abnormalities in behavior or physiology. However, upon thorough testing, a number of psychometric studies have revealed subtle cognitive/ memory deficits in abstinent MDMA users (Verbaten, 2003). Although it remains to be established that these memory abnormalities, if due specifically to MDMA, are directly related to serotonergic deficits, controlled studies in which indices of serotonin neuronal integrity are assessed in conjunction with detailed cognitive assessments should help to address this question.

The reasons for the failure to detect significant differences between SERT-binding parameters in a number of subcortical brain regions high in SERT density is, at first, puzzling. Indeed, we (McCann et al, 1998) and other researchers (Buchert et al, 2003) have previously noted a reduction in SERT-binding sites in some of these regions. Evaluation of the data in subcortical regions (ie putamen, midbrain) in the present study indicates a high level of variability relative to other brain regions where significant differences were identified. The reasons for the high 

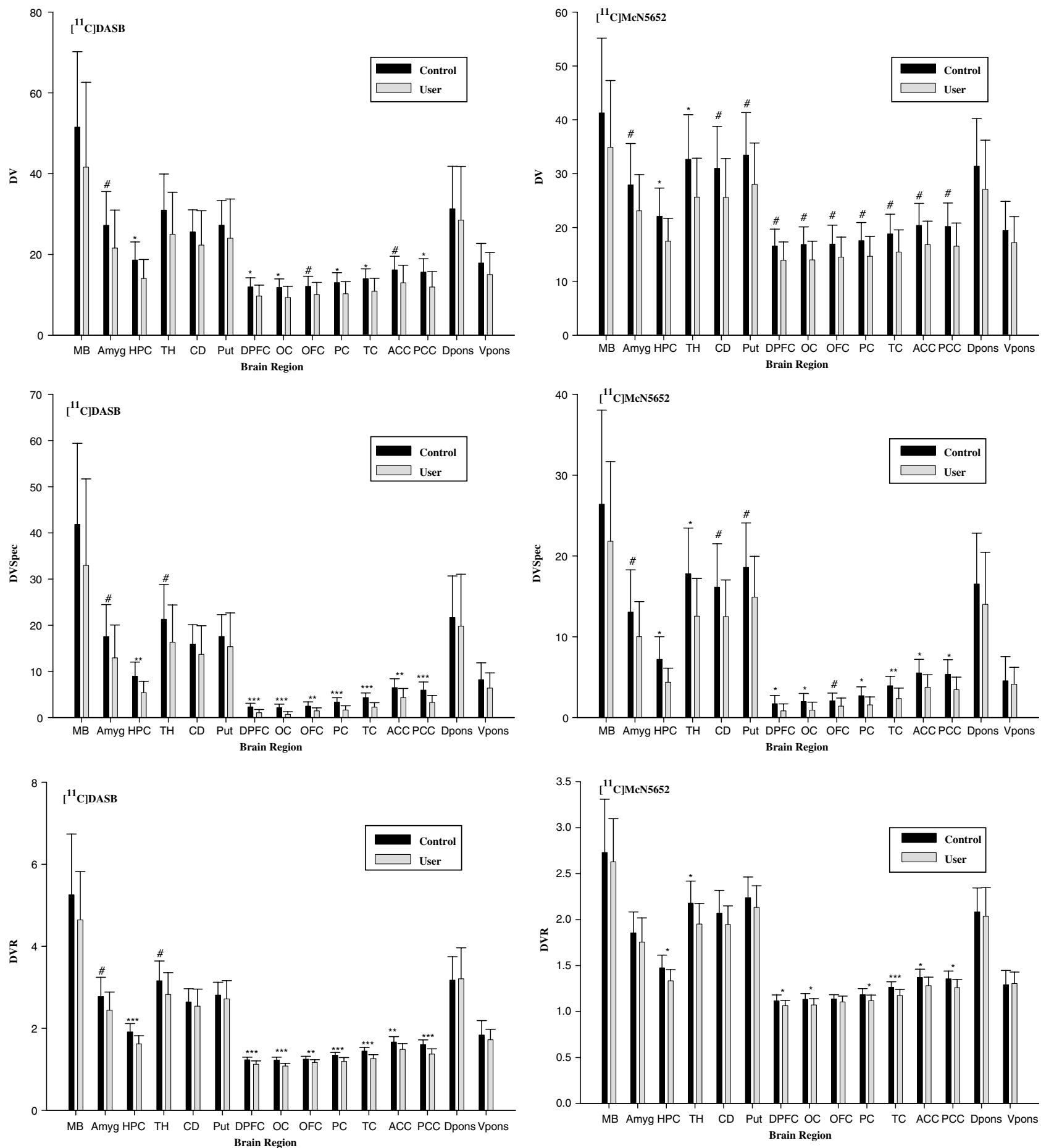

Figure 4 Serotonin transporter-binding parameters in MDMA users and controls are shown, as measured by PET with [ $\left.{ }^{\prime \prime} \mathrm{C}\right] \mathrm{DASB}$ and $\left[{ }^{\prime \prime} \mathrm{C}\right] \mathrm{McN} 5652$ using the three binding parameters, DV ( $\mathrm{ml} / \mathrm{ml} \pm \mathrm{SD}$; top row), $D V_{\text {spec }}(\mathrm{ml} / \mathrm{ml} \pm \mathrm{SD}$; middle row), and DVR $\pm S D$ (bottom row). Levels of significance are designated as follows: \# $\leqslant 0.05$; * <0.01; *** <0.00 I; *****0.000I. Abbrevations of brain regions are as follows: MB, midbrain; Amyg, amygdala; HPC, hippocampus; TH, thalamus; CD, caudate; Put, putamen; DPFC, dorsolateral prefrontal cortex; OC, occipital cortex; OFC, orbitofrontal cortex; PC, parietal cortex; TC, temporal cortex; ACC, anterior cingulate cortex; PCC, posterior cingulate cortex; Dpons, dorsal pons; Vpons, ventral pons.

variability in subcortical regions are likely to be multiple (see above). Also, in MDMA subjects, possible regeneration of serotonin axons and axon terminals from raphe nerve cell bodies, which are known to be unaffected by MDMA (Green et al, 2003; Hatzidimitriou et al, 1999) may contribute to variability in subcortical regions. Thus, the potential for recovery over time, coupled with the fact that recovery is not uniform among various brain regions, may be a source of variability in abstinent MDMA users who have different durations of abstinence. When considered with the fact that, unlike experimental animals, most MDMA users do not have a single exposure regimen of 
Table 3 Percent Differences and SD for Both Tracers for the DV $V_{\text {Spec }}$ Analytic Method, Shown by Each Region of Interest

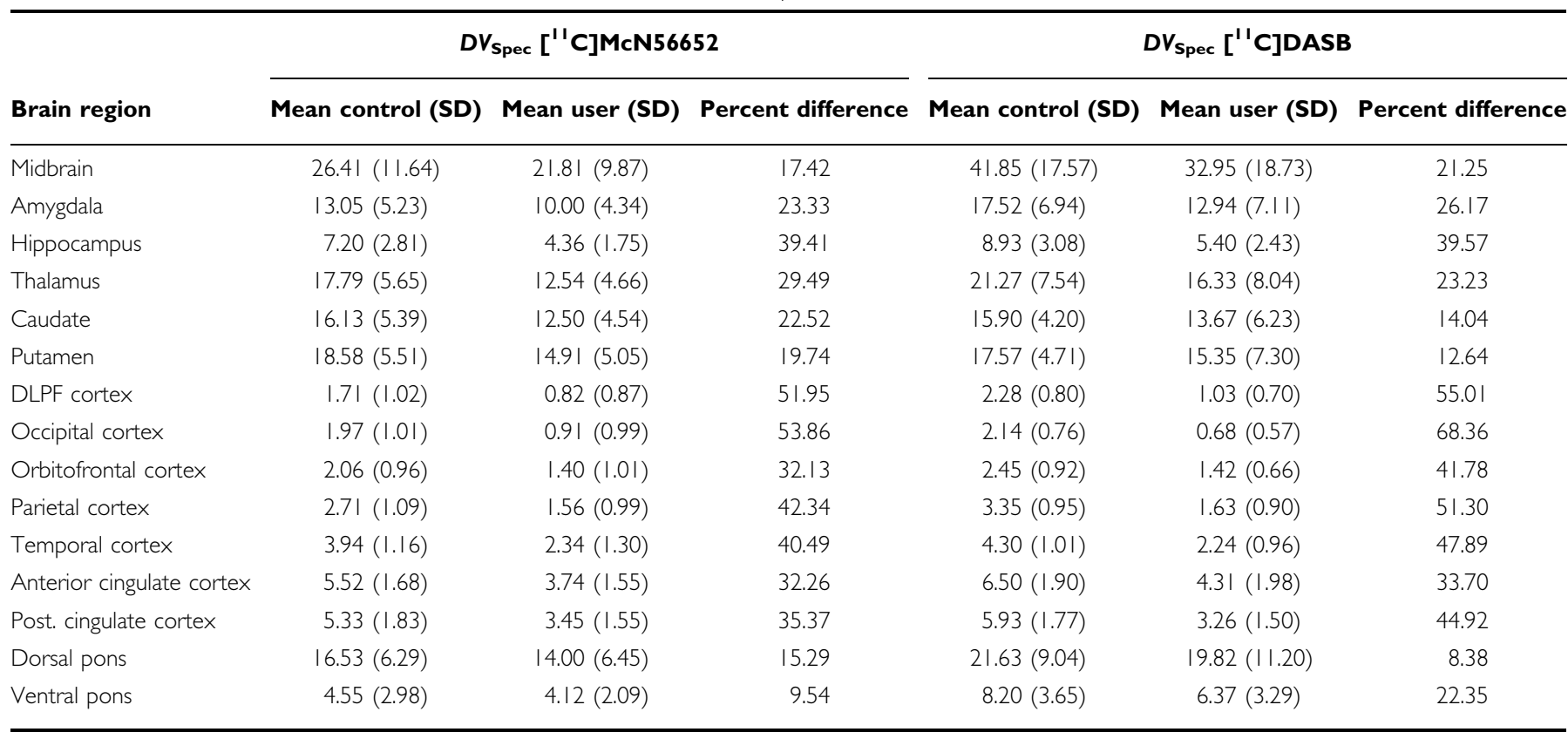

MDMA but, instead, tend to use MDMA over months to years, interpretation of neuroimaging studies in MDMA users poses challenges.

Exploratory analyses suggested a positive relationship between SERT binding and duration of abstinence, and a negative relationship between SERT-binding parameters and MDMA use intensity (as measured by self-reported typical monthly MDMA consumption). These data are consistent with preclinical data (Hatzidimitriou et al, 1999), which demonstrate recovery of serotonin axonal terminals in some (but not all) brain regions over time, and a doserelated MDMA-induced serotonin neurotoxic response (Green et al, 2003). However, they must be interpreted with caution and considered preliminary because, as mentioned above, MDMA users in this study had multiple exposures to MDMA, and our study was not powered to demonstrate significant correlations between SERT-binding parameters and use parameters.

Limitations of this study should be recognized. First, as noted previously (and in Table 1), MDMA users tended to use more 'other' recreational drugs (licit and illicit) than controls, despite considerable efforts to match the two groups on this factor. The difficulty in matching subjects on this feature stems from the fact that MDMA users who met criteria for study inclusion (ie use on at least 25 separate occasions), as a rule, used a number of other recreational drugs as well. Therefore, the possibility remains open that 'other drug' use, alone or in interaction with MDMA, may play a role in SERT reductions noted in MDMA users. Second, even if MDMA subjects' retrospective accounts of their drug use histories are fully accurate, it is impossible to verify whether drugs believed to be MDMA were pure, or whether they were adulterated with other drugs that may have influenced SERT binding. Finally, it is possible that reductions in SERT binding in MDMA users pre-existed MDMA use. Although subjects with neuropsychiatric diagnoses and conditions in which serotonin has been implicated were excluded from participation, it is possible that an unidentified condition that predisposes individuals to use recreational drugs played a role in SERT reductions in MDMA users.

In conclusion, quantitative PET results from the current study extend previous observations obtained with $\left[{ }^{11} \mathrm{C}\right] \mathrm{McN} 5652$ to $\left[{ }^{11} \mathrm{C}\right] \mathrm{DASB}$. Together, studies with firstand second-generation SERT radiotracers in the same individual demonstrate that abstinent MDMA users have reductions in regional brain SERT. Notably, results obtained using two SERT radiotracers in the same subjects were highly consistent, using a variety of SERT-imaging parameters. Although both tracers were found to be capable of detecting MDMA-related reductions in regional brain SERT binding, results obtained using $\left[{ }^{11} \mathrm{C}\right] \mathrm{DASB}$ were more robust. Future studies are needed to determine the lower limits at which PET is capable of detecting loss of the SERT, and whether individuals with lower exposure to MDMA also demonstrate losses of the brain SERT. In addition, studies aimed at determining the potential relationship between brain measures of the SERT and functional consequences of MDMA may be useful in elucidating the role of the serotonin system in normal brain function and in various neuropsychiatric disease states.

\section{ACKNOWLEDGEMENTS}

This manuscript was supported by PHS Grants DA10217 (McCann); AA11653 (Szabo) DA00206 (Ricaurte), and NCRR grant M01RR002719 (Klag). We thank Paul Nuzzo for his assistance with statistical analyses, and Audra de Ridder and Anna Du Val for their assistance with recruiting and preparing the manuscript. We appreciate the following contributions to PET imaging and image analysis: Jozsef 
Varga, $\mathrm{PhD}$, for the software design and implementation of the PMT software package that was used for image registration and ROI analysis; Tomas Zober, MD, for determinations of the input functions, computer network, and database management; David Clough CNMT and Karen Edmonds, CNMT for performance of PET studies; John Hilton for HPLC analysis of tracer metabolites; and Alan Wilson and Sylvain Houle for their generous assistance in the development of DASB imaging methods at our institution. None of the authors has a financial or other conflict of interest that might potentially bias this work.

\section{REFERENCES}

Battaglia G, Yeh SY, De Souza EB (1988). MDMA-induced neurotoxicity: parameters of degeneration and recovery of brain serotonin neurons. Pharmacol Biochem Behav 29: 269-274.

Battaglia G, Yeh SY, O'Hearn E, Molliver ME, Kuhar MJ, De Souza EB (1987). 3,4-Methylenedioxymethamphetamine and 3,4methylenedioxyamphetamine destroy serotonin terminals in rat brain: quantification of neurodegeneration by measurement of $\left[{ }^{3} \mathrm{H}\right]$ paroxetine-labeled serotonin uptake sites. J Pharmacol Exp Ther 242: 911-916.

Buchert R, Thomasius R, Nebeling B, Petersen K, Obrocki J, Jenicke L et al (2003). Long-term effects of 'ecstasy' use on serotonin transporters of the brain investigated by PET. J Nucl Med 44: 375-384.

Buchert R, Thomasius R, Wilke F, Petersen K, Nebeling B, Obrocki $\mathrm{J}$ et al (2004). A voxel-based PET investigation of the long-term effects of 'ecstasy' consumption on brain serotonin transporters. Am J Psychiatry 161: 1181-1189.

Callahan BT, Cord BJ, Ricaurte GA (2001). Long-term impairment of anterograde axonal transport along fiber projections originating in the rostral raphe nuclei after treatment with fenfluramine or methylenedioxymethamphetamine. Synapse 40: 113-121.

Commins DL, Vosmer G, Virus RM, Woolverton WL, Schuster CR, Seiden LS (1987). Biochemical and histological evidence that methylenedioxymethylamphetamine (MDMA) is toxic to neurons in the rat brain. J Pharmacol Exp Ther 241: 338-345.

First MB, Spitzer RL, Gibbon M, Williams JBW (1996). Structured Clinical Interview for DSM-IV Axis I Disorders-Patient Edition (SCID-I/P, version 2.0). Biometrics Research Department New York Psychiatric Institute: New York, NY.

Frankle WG, Huang Y, Hwang DR, Talbot PS, Slifstein M, Van Heertum $\mathrm{R}$ et al (2004). Comparative evaluation of serotonin transporter radioligands 11C-DASB and $11 \mathrm{C}-\mathrm{McN} 5652$ in healthy humans. J Nucl Med 45: 682-694.

Green AR, Mechan AO, Elliott JM, O'Shea E, Colado MI (2003). The pharmacology and clinical pharmacology of 3,4-methylenedioxymethamphetamine (MDMA, 'ecstasy'). Pharmacol Rev 55: 463-508.

Haddad PM, Strickland P, Anderson I, Deakin JF, Dursun SM (2002). Effects of MDMA (ecstasy) use and abstention on serotonin neurons. Lancet 359: 1616-1617; author reply 1617-1618.

Hatzidimitriou G, McCann UD, Ricaurte GA (1999). Altered serotonin innervation patterns in the forebrain of monkeys treated with (+/-)3,4-methylenedioxymethamphetamine seven years previously: factors influencing abnormal recovery. $J$ Neurosci 19: 5096-5107.

Hilton J, Yokoi F, Dannals RF, Ravert HT, Szabo Z, Wong DF (2000). Column-switching HPLC for the analysis of plasma in PET imaging studies. Nucl Med Biol 27: 627-630.

Houle S, Ginovart N, Hussey D, Meyer JH, Wilson AA (2000). Imaging the serotonin transporter with positron emission tomography: initial human studies with $\left[{ }^{11} \mathrm{C}\right] \mathrm{DAPP}$ and $\left[{ }^{11}\right.$ C]DASB. Eur J Nucl Med 27: 1719-1722.

Johnston LD, O’Malley PM, Bachman JG, Schulenberg E (2004). Monitoring the Future National Results on Adolescent Drug Use: Overview of Key Findings. 2003 NIH Publication No. 04-5506. National Institute on Drug Abuse: Bethesda.

Marquardt DW (1963). An algorithm for least-squares estimation of non-linear parameters. J Soc Indust Appl Math 11: 431-441.

McCann UD, Eligulashvili V, Ricaurte GA (2000). 3,4-Methylenedioxymethamphetamine ('Ecstasy')-induced serotonin neurotoxicity: clinical studies. Neuropsychobiology 42: 11-16.

McCann UD, Mertl M, Eligulashvili V, Ricaurte GA (1999). Cognitive performance in (+/-) 3,4-methylenedioxymethamphetamine (MDMA, 'ecstasy') users: a controlled study. Psychopharmacology (Berl) 143: 417-425.

McCann UD, Ridenour A, Shaham Y, Ricaurte GA (1994). Serotonin neurotoxicity after (+/-)3,4-methylenedioxymethamphetamine (MDMA; 'Ecstasy'): a controlled study in humans. Neuropsychopharmacology 10: 129-138.

McCann UD, Szabo Z, Scheffel U, Dannals RF, Ricaurte GA (1998). Positron emission tomographic evidence of toxic effect of MDMA ('Ecstasy') on brain serotonin neurons in human beings. Lancet 352: 1433-1437.

Meyer JH, Wilson AA, Ginovart N, Goulding V, Hussey D, Hood K et al (2001). Occupancy of serotonin transporters by paroxetine and citalopram during treatment of depression: a [(11)C]DASB PET imaging study. Am J Psychiatry 158: 1843-1849.

O'Hearn E, Battaglia G, De Souza EB, Kuhar MJ, Molliver ME (1988). Methylenedioxyamphetamine (MDA) and methylenedioxymethamphetamine (MDMA) cause selective ablation of serotonergic axon terminals in forebrain: immunocytochemical evidence for neurotoxicity. J Neurosci 8: 2788-2803.

Reneman L, Booij J, de Bruin K, Reitsma JB, de Wolff FA, Gunning WB et al (2001a). Effects of dose, sex, and long-term abstention from use on toxic effects of MDMA (ecstasy) on brain serotonin neurons. Lancet 358: 1864-1869.

Reneman L, Lavalaye J, Schmand B, de Wolff FA, van den Brink W, den Heeten GJ et al (2001b). Cortical serotonin transporter density and verbal memory in individuals who stopped using 3,4-methylenedioxymethamphetamine (MDMA or 'ecstasy'): preliminary findings. Arch Gen Psychiatry 58: 901-906.

Ricaurte GA, DeLanney LE, Wiener SG, Irwin I, Langston JW (1988). 5-Hydroxyindoleacetic acid in cerebrospinal fluid reflects serotonergic damage induced by 3,4-methylenedioxymethamphetamine in CNS of non-human primates. Brain Res 474: 359-363.

Scheffel U, Szabo Z, Mathews WB, Finley PA, Dannals RF, Ravert $\mathrm{HT}$ et al (1998). In vivo detection of short- and long-term MDMA neurotoxicity - a positron emission tomography study in the living baboon brain. Synapse 29: 183-192.

Schmidt CJ (1987). Neurotoxicity of the psychedelic amphetamine, methylenedioxymethamphetamine. J Pharmacol Exp Ther 240: $1-7$.

Schmidt CJ, Taylor VL (1987). Depression of rat brain tryptophan hydroxylase activity following the acute administration of methylenedioxymethamphetamine. Biochem Pharmacol 36: 4095-4102.

Schmidt CJ, Wu L, Lovenberg W (1986). Methylenedioxymethamphetamine: a potentially neurotoxic amphetamine analogue. Eur J Pharmacol 124: 175-178.

Semple DM, Ebmeier KP, Glabus MF, O'Carroll RE, Johnstone EC (1999). Reduced in vivo binding to the serotonin transporter in the cerebral cortex of MDMA ('ecstasy') users. Br J Psychiatry 175: 63-69.

Stone DM, Merchant KM, Hanson GR, Gibb JW (1987). Immediate and long-term effects of 3,4-methylenedioxymethamphetamine on serotonin pathways in brain of rat. Neuropharmacology 26: 1677-1683. 
Stone DM, Stahl DC, Hanson GR, Gibb JW (1986). The effects of 3,4-methylenedioxymethamphetamine (MDMA) and 3,4-methylenedioxyamphetamine (MDA) on monoaminergic systems in the rat brain. Eur J Pharmacol 128: 41-48.

Suehiro M, Scheffel U, Dannals RF, Wilson AA, Ravert HT, Wagner Jr HN (1992). Synthesis and biodistribution of a new radiotracer for in vivo labeling of serotonin uptake sites by PET, cis- $N, N-\left[{ }^{11} \mathrm{C}\right]$ dimethyl-3- $\left(2^{\prime}, 4^{\prime}\right.$-dichlorophenyl)-indanamine (cis- $\left.\left[{ }^{11} \mathrm{C}\right] \mathrm{DDPI}\right)$. Int J Rad Appl Instrum B 19: 549-553.

Szabo Z, McCann UD, Wilson AA, Scheffel U, Owonikoko T, Mathews WB et al (2002). Comparison of (+)-(11)C-McN5652 and (11)C-DASB as serotonin transporter radioligands under various experimental conditions. J Nucl Med 43: 678-692.

Szabo Z, Owonikoko T, Peyrot M, Varga J, Mathews WB, Ravert HT et al (2004). Positron emission tomography imaging of the serotonin transporter in subjects with a history of alcoholism. Biol Psychiatry 55: 766-771.

Szabo Z, Scheffel U, Mathews WB, Ravert HT, Szabo K, Kraut M, Palmon $S$ et al (1999). Kinetic analysis of $\left[{ }^{11} \mathrm{C}\right] \mathrm{McN} 5652$ : a serotonin transporter radioligand. J Cereb Blood Flow Metab 19: 967-981.

Taffe MA, Davis SA, Yuan J, Schroeder R, Hatzidimitriou G, Parsons LH et al (2002). Cognitive performance of MDMAtreated rhesus monkeys: sensitivity to serotonergic challenge. Neuropsychopharmacology 27: 993-1005.

Verbaten MN (2003). Specific memory deficits in ecstasy users. The results of a meta-analysis. Hum Psychopharmacol 18: $281-290$.

Wilson AA, Ginovart N, Schmidt M, Meyer JH, Threlkeld PG, Houle S (2000). Novel radiotracers for imaging the serotonin transporter by positron emission tomography: synthesis, radiosynthesis, and in vitro and ex vivo evaluation of (11)Clabeled 2-(phenylthio)araalkylamines. J Med Chem 43: 31033110.

Yuan J, Tong L, Xie T, McCann UD, Ricaurte GA (2004). Detection of Serotonin Transporter Protein Loss Following Treatment with Serotonin Neurotoxins Society for Neuroscience, 2004. Society for Neuroscience: San Diego. 